\title{
Computational Approach for Multi Performances Optimization of EDM
}

\author{
Yusliza Yusoff ${ }^{1, *}$, Azlan Mohd Zain ${ }^{1}$, Mohd Salihin Ngadiman ${ }^{1}$ \\ ${ }^{1}$ Department of Computer Science, Faculty of Computing, 81310 UTM Skudai, Johor, Malaysia
}

\begin{abstract}
This paper proposes a new computational approach employed in obtaining optimal parameters of multi performances EDM. Regression and artificial neural network (ANN) are used as the modeling techniques meanwhile multi objective genetic algorithm (multiGA) is used as the optimization technique. Orthogonal array L256 is implemented in the procedure of network function and network architecture selection. Experimental studies are carried out to verify the machining performances suggested by this approach. The highest MRR value obtained from OrthoANN - MPR - MultiGA is $205.619 \mathrm{mg} / \mathrm{min}$ and the lowest Ra value is $0.0223 \mu \mathrm{m}$.
\end{abstract}

\section{Introduction}

The high operational cost, long experimental period and requirement of an experienced machinist resulted to the aggressive research development in the area of machining optimization of EDM. Based on the literatures, there are four major issues in EDM which are monitored and control, machining, development, handling of parts and parameters optimization $[1,2]$.

In this paper, we are focusing on the computational approaches to optimize and improve the multiple machining performances of EDM. Traditionally, machining parameters are selected manually based on the engineer and operator experiences [3]. The selection of parameters in order to obtain the optimum machining performances is very complex due to the best parameter combination is unknown especially to the beginners and non machining expertise. Improper variables guesswork has contributed to a long development period, miss achieve of target date and loss of competitiveness. In general, during the early stage of development, the engineers and operators have a very limited processing knowledge to complete the machining experiments within the time given resulted in a very high development cost. To overcome difficulties in obtaining optimal solutions in a fast manner and low cost, new intelligent modeling and optimization techniques are proposed. There are many intelligent techniques proposed in optimizing machining operations as described by Rao and Kalyankar (2014) [4].

There are many modeling techniques proposed by previous researchers such as response surface methodology (RSM), regression, ANN, support vector machine (SVM) [5], fuzzy logic (FL) [6] etc. For example, Padhee et al. (2012) [7] adopted RSM to model, and NSGA

\footnotetext{
*Corresponding author: yusliza@utm.my
} 
to optimize the machining parameters; dielectric fluid, pulse on time, duty cycle and peak current of powder mixed EDM. Regression is also considered as one of the most well known modeling technique employed by many researchers to overcome the machining optimization problems as mentioned by Zain et al. (2012) [8]. Zain et al. (2012) [8] in their study, applied regression and ANN model to optimize the surface roughness value of an end milling machining. In this paper, we are focusing on combining regression, ANN and multiGA to optimize multiple performances of EDM. Different from existing literatures which uses variable numerical experimentation [9] or random selection [10-12], we proposed orthogonal array as a technique to select the network parameters of ANN modeling in this study. Basically, the used of orthogonal array L256, is targeted to reduce the trial and error guesswork during the network parameters and network architecture selection. The regression and ANN model are then executed with multiGA in order to obtain the optimal machining solutions. Although there are many new optimization algorithms, such as cuckoo search algorithm [13], Levy flight algorithm [14], glowworm swarm algorithm [15], firefly algorithm [16], GA has taken a wide range of monopoly in solving the machining parameters optimization problems as surveyed by Yusup et al. (2012) [17] due to its advantages; mainly in reducing operational cost and production time besides maximizing the production rate and quality. In terms of multiple objectives, the journey of multiGA in machining optimization is still untapped and a continuous initiative on how to obtain optimal multiple machining performances need to be determined.

\section{Experimental}

The experimental data used in this study are obtained from experiments conducted by Kanagarajan et al. (2008) [18] in an Electronica die sinking EDM. The electrode material used by the authors is an electrolytic grade copper with the size of $12 \mathrm{~mm}$ diameter. Kerosene is used as the dielectric fluid circulated by the jet flushing and the composites of the workpiece materials consist of $70 \%$ tungsten carbide and $30 \%$ cobalt. The machining performances considered are material removal rate (MRR) and surface roughness (Ra); meanwhile the parameters are rotation $(\mathrm{S})$, current $(\mathrm{T})$, pulse on time $(\mathrm{U})$, flushing pressure (V).

ANN. The difficulty to predict expected output characteristic of EDM using mathematical equation resulted in the idea of using computational integration of ANN and MPR. The special logical characteristic of ANN which is easily constructed based on the input and output training data; the integration of these two models, ANN-MPR is expected to predict better optimal machining parameters. Besides that, the ability to completely detect complex nonlinear relationships between dependent and independent multiple variables is aimed to support MultiGA in generating considerable optimal solutions. The only problem heading with ANN is when there will be too much guesswork in choosing the best network functions. To avoid time consuming and trial error experimentation, we include orthogonal array L256 in the process of selection combination. The network functions are arranged based on the L256 combinatorial design. From the orthogonal array results, it is observed that 4-8-2 layer recurrent neural network (LRNN) architecture as depicted in Fig. 1 is found to be the most accurate and reliable with very good prediction accuracy. 4-8-2 LRNN, or generally prescribed as OrthoANN showed the lowest percent error; $1.74 \%$ for MRR and $1.80 \%$ for Ra with the configuration of Bayesian Regulation training function, hyperbolic tangent sigmoid transfer function, mean squared error performance function and gradient descent weight and bias learning function. The predicted results of OrthoANN and the percent error compared to real machining data are given in Table 2. 
MPR. A statistical regression equation, known as multiple polynomial regression (MPR) is employed as part of the modeling technique of this study. The basic MPR equations of this study are given as Eq. 1(MRR) and Eq. 2 (Ra) below:

$$
\begin{gathered}
\mathrm{MRR}=\mathrm{M} 1 \mathrm{~S}+\mathrm{M} 2 \mathrm{~T}+\mathrm{M} 3 \mathrm{U}+\mathrm{M} 4 \mathrm{~V}+\mathrm{M} 5 \mathrm{~S} 2+\mathrm{M} 6 \mathrm{~T} 2+\mathrm{M} 7 \mathrm{U} 2+\mathrm{M} 8 \mathrm{~V} 2+\mathrm{C} \\
\mathrm{Ra}=\mathrm{N} 1 \mathrm{~S}+\mathrm{N} 2 \mathrm{~T}+\mathrm{N} 3 \mathrm{U}+\mathrm{N} 4 \mathrm{~V}+\mathrm{N} 5 \mathrm{~S} 2+\mathrm{N} 6 \mathrm{~T} 2+\mathrm{N} 7 \mathrm{U} 2+\mathrm{N} 8 \mathrm{~V} 2+\mathrm{C}
\end{gathered}
$$

Where, M1 M8 and N1 N8 are the coefficients, S, T, U, V are the considered parameter variables and $\mathrm{C}$ is the constant value.
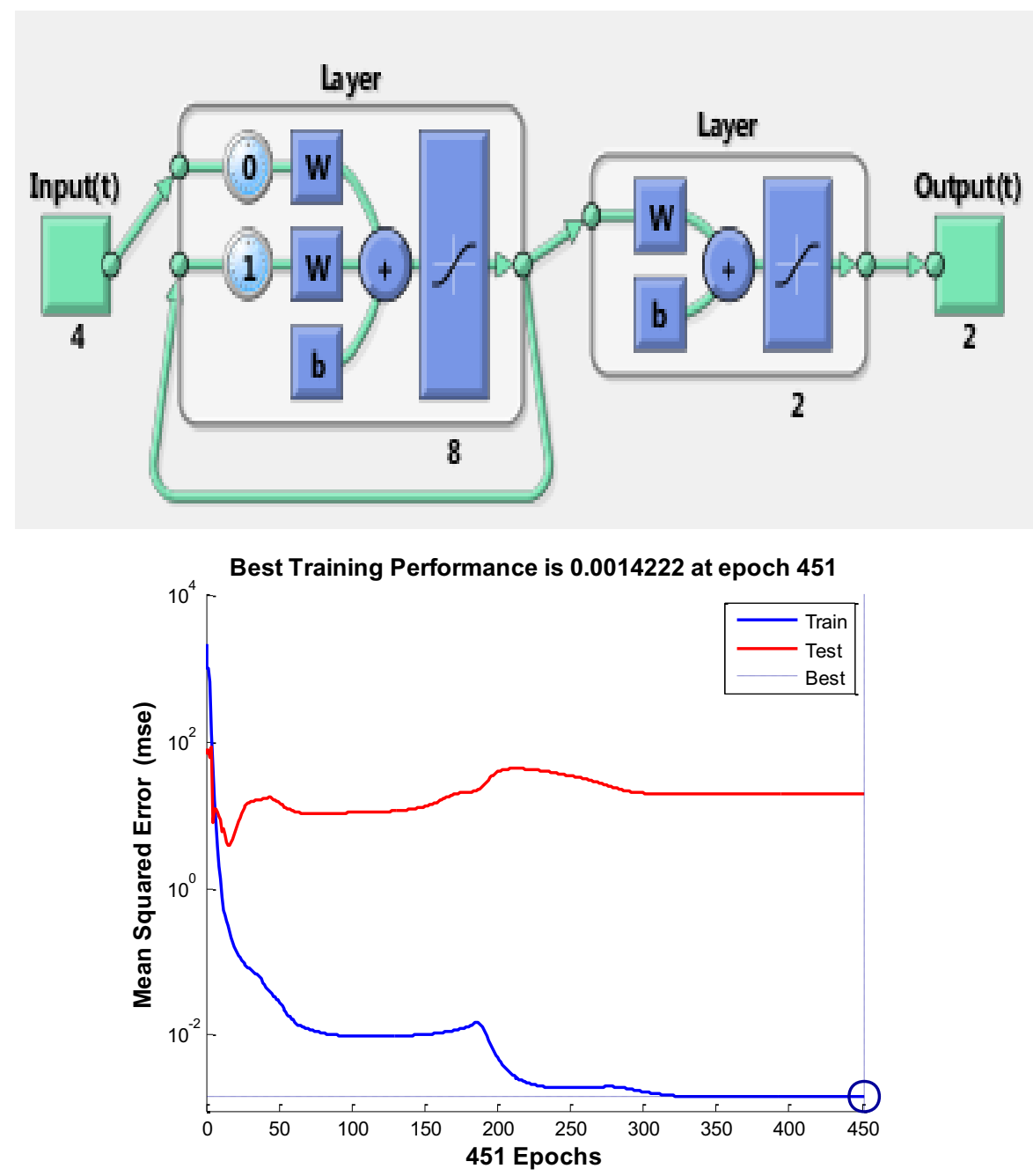

Fig. 1. 4-8-2 LRNN architecture and training performance. 
Table 2. Real machining results and OrthoANN results.

\begin{tabular}{|c|c|c|c|c|c|c|c|c|c|c|}
\hline \multirow{2}{*}{$\underset{\Xi}{\stackrel{2}{\Xi}}$} & \multicolumn{6}{|c|}{ Real EDM Experiment (Kanagarajan et al, 2008) } & \multicolumn{4}{|c|}{ OrthoANN Prediction Resutls } \\
\hline & $\begin{array}{l}\text { Rotational } \\
\text { speed, } \\
\text { rpm (S) }\end{array}$ & $\begin{array}{c}\text { Current, } \\
\text { A (T) }\end{array}$ & $\begin{array}{l}\text { Pulse } \\
\text { Time, } \\
\text { us (U) }\end{array}$ & $\begin{array}{l}\text { Flushing } \\
\text { pressure, } \\
\mathrm{kg} / \mathrm{cm}^{2}(\mathrm{~V})\end{array}$ & $\begin{array}{l}\mathrm{MRR} \\
\mathrm{mg} / \mathrm{min}\end{array}$ & $\begin{array}{l}\mathrm{Ra}, \\
\mu \mathrm{m}\end{array}$ & $\begin{array}{l}\mathrm{MRR} \\
\mathrm{mg} / \mathrm{min}\end{array}$ & $\begin{array}{l}\text { Percent } \\
\text { error, } \%\end{array}$ & $\mathrm{Ra}, \mu \mathrm{m}$ & $\begin{array}{l}\text { Percent } \\
\text { error, \% }\end{array}$ \\
\hline 1 & 250 & 5 & 200 & 0.5 & 38.19 & 3.94 & 38.19838 & 0.00022 & 3.92347 & 0.004195 \\
\hline 2 & 250 & 5 & 200 & 1 & 46.05 & 2.84 & 39.87993 & 0.133986 & 2.978744 & 0.048853 \\
\hline 3 & 250 & 5 & 200 & 1.5 & 51.37 & 2.35 & 51.36999 & $2.78 \mathrm{E}-07$ & 2.386609 & 0.015578 \\
\hline 4 & 250 & 10 & 500 & 0.5 & 46.5 & 8.83 & 46.49825 & $3.77 \mathrm{E}-05$ & 8.831211 & 0.000137 \\
\hline 5 & 250 & 10 & 500 & 1 & 56.07 & 6.37 & 56.07072 & $1.28 \mathrm{E}-05$ & 6.374118 & 0.000646 \\
\hline 6 & 250 & 10 & 500 & 1.5 & 62.56 & 5.27 & 61.25816 & 0.020809 & 4.407064 & 0.163745 \\
\hline 7 & 250 & 15 & 1000 & 0.5 & 49.31 & $\begin{array}{c}14.7 \\
4\end{array}$ & 49.31042 & $8.54 \mathrm{E}-06$ & 14.56681 & 0.01175 \\
\hline 8 & 250 & 15 & 1000 & 1 & 59.45 & $\begin{array}{c}10.6 \\
4\end{array}$ & 59.4498 & $3.44 \mathrm{E}-06$ & 10.6538 & 0.001297 \\
\hline 9 & 250 & 15 & 1000 & 1.5 & 66.33 & 8.8 & 66.33009 & $1.37 \mathrm{E}-06$ & 8.793185 & 0.000774 \\
\hline 10 & 500 & 5 & 500 & 0.5 & 37.77 & 3.89 & 42.02465 & 0.112646 & 3.561823 & 0.084364 \\
\hline 11 & 500 & 5 & 500 & 1 & 45.54 & 2.81 & 45.53809 & $4.2 \mathrm{E}-05$ & 2.82346 & 0.00479 \\
\hline 12 & 500 & 5 & 500 & 1.5 & 50.81 & 2.39 & 50.81059 & $1.16 \mathrm{E}-05$ & 2.377658 & 0.005164 \\
\hline 13 & 500 & 10 & 1000 & 0.5 & 49.84 & 8.24 & 49.84137 & $2.75 \mathrm{E}-05$ & 8.246744 & 0.000818 \\
\hline 14 & 500 & 10 & 1000 & 1 & 60.09 & 5.94 & 60.08888 & $1.87 \mathrm{E}-05$ & 5.927781 & 0.002057 \\
\hline 15 & 500 & 10 & 1000 & 1.5 & 67.05 & 4.91 & 67.05043 & $6.42 \mathrm{E}-06$ & 4.915196 & 0.001058 \\
\hline 16 & 500 & 15 & 200 & 0.5 & 121.07 & 7.56 & 121.0698 & $1.38 \mathrm{E}-06$ & 7.559584 & $5.5 \mathrm{E}-05$ \\
\hline 17 & 500 & 15 & 200 & 1 & 145.98 & 5.45 & 145.9803 & $2.22 \mathrm{E}-06$ & 5.443669 & 0.001162 \\
\hline 18 & 500 & 15 & 200 & 1.5 & 162.87 & 4.51 & 162.8678 & $1.33 \mathrm{E}-05$ & 4.516236 & 0.001383 \\
\hline 19 & 1000 & 5 & 1000 & 0.5 & 40.48 & 3.63 & 40.48258 & $6.38 \mathrm{E}-05$ & 3.643697 & 0.003773 \\
\hline 20 & 1000 & 5 & 1000 & 1 & 48.81 & 2.62 & 38.94707 & 0.202068 & 2.905432 & 0.108944 \\
\hline 21 & 1000 & 5 & 1000 & 1.5 & 54.46 & 2.37 & 54.4608 & $1.47 \mathrm{E}-05$ & 2.371298 & 0.000548 \\
\hline 22 & 1000 & 10 & 1000 & 0.5 & 122.37 & 4.22 & 122.3699 & $1.22 \mathrm{E}-06$ & 4.221237 & 0.000293 \\
\hline 23 & 1000 & 10 & 1000 & 1 & 147.55 & 3.05 & 147.5507 & $4.45 \mathrm{E}-06$ & 3.032144 & 0.005854 \\
\hline 24 & 1000 & 10 & 1000 & 1.5 & 164.62 & 2.52 & 164.445 & 0.001063 & 2.479962 & 0.015888 \\
\hline 25 & 1000 & 15 & 1000 & 0.5 & 119.74 & 7.47 & 119.7401 & $8.68 \mathrm{E}-07$ & 7.472861 & 0.000383 \\
\hline 26 & 1000 & 15 & 1000 & 1 & 144.38 & 5.39 & 144.38 & $2.48 \mathrm{E}-10$ & 5.397557 & 0.001402 \\
\hline 27 & 1000 & 15 & 1000 & 1.5 & 161.09 & 4.46 & 161.0933 & $2.05 \mathrm{E}-05$ & 4.456306 & 0.000828 \\
\hline & & & age 1 & rror & & & & $1.74 \%$ & & $1.80 \%$ \\
\hline
\end{tabular}

MultiGA. GA is able to search for better solutions to linear and nonlinear problems through mutation, crossover and selection operations. The goals of multi objectives optimization are to find set of solutions near to the Pareto optimal front and should uniformly distributed. MultiGA which uses controlled elitist GA, a variation of NSGA-II [19] is used to generate the Pareto frontier of this study. MultiGA acts on individuals with better fitness value that can help to increase the diversity of the population even if they have a lower fitness value. It is very important to preserve the diversity of population for convergence to an optimal Pareto front by controlling the elite members of the algorithm. The optimization algorithm is run in Matlab 2012 software. The objective functions of this study are to maximize MRR and minimize Ra based on basic equation as shown by Eq. 1 and Eq. 2. The optimization trials have been conducted accordingly based on selected algorithm parameters and limitations. The algorithm parameters considered are: population size of 60 , generation size of 800 , tournament selection value of 2 , intermediate crossover value of 1 and adaptive feasible mutation. 4-8-2 LRNN OrthoANN - MPR - MultiGA results are presented in Fig. 2. The results obtained at 542 iterations. 

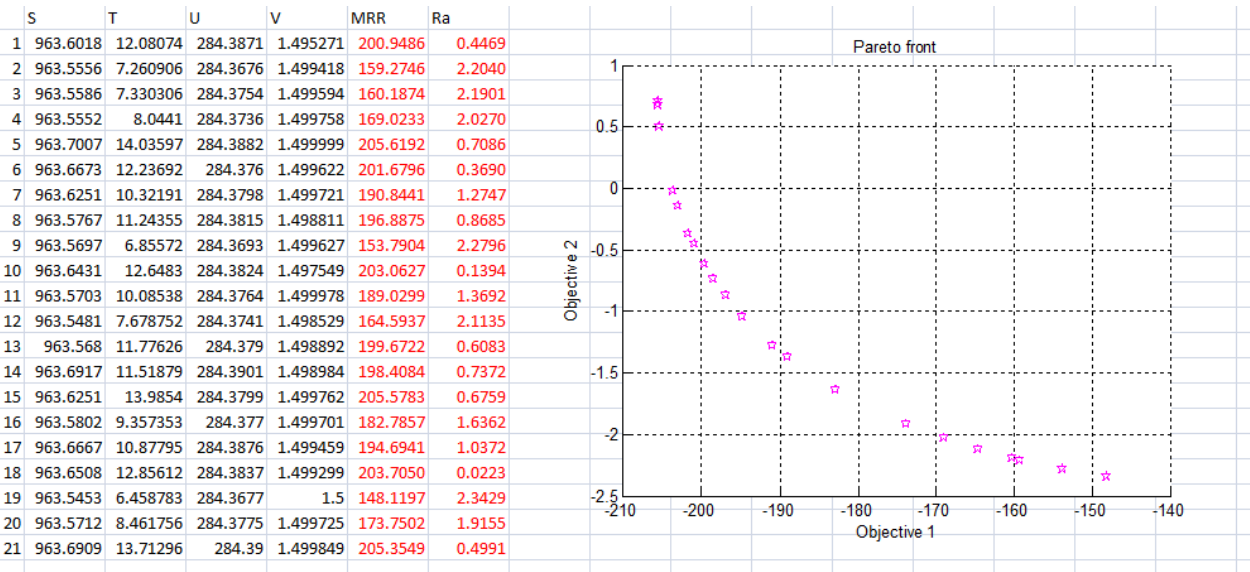

Fig. 2. OrthoANN - MPR - MultiGA optimal solutions.

\section{Discussion and conclusion}

From the experimental results of OrthoANN - MPR - MultiGA, presented in Fig. 2, none of the solutions is absolutely better than any other solution, the best solution can be selected based on the individual product requirements. The option of one solution over the other depends on the requirement. If the requirement is a better surface roughness or higher material removal rate, a suitable arrangement of variables can be decided. As for this study, the objectives are to maximize the MRR value, and minimize Ra value. From real EDM experimental results presented in Table 2, the highest MRR value obtained is 164.62 $\mathrm{mg} / \mathrm{min}$ for solution no. 24 , meanwhile the lowest Ra value is $2.35 \mu \mathrm{m}$ from solution no. 3 . Contrast to OrthoANN - MPR - MultiGA results, most of the MRR solutions are higher than the value obtained by experiment. The highest MRR value is $205.6192 \mathrm{mg} / \mathrm{min}$ from solution no. 5 and the lowest MRR value obtained is $148.1197 \mathrm{mg} / \mathrm{min}$ from solution no. 19 . As depicted in Fig. 2, only solutions 2, 3, 9, 12, 19 showed lower values than the real experimental MRR highest value. The lowest Ra solution from Fig. 2 is $0.0223 \mu \mathrm{m}$ which is much lower than the real experimental values.

Special appreciation to reviewer(s) for useful advices and comments. The authors greatly acknowledge the Research Management Centre, UTM and Ministry of Higher Education Malaysia (MOHE) for financial support through the Fundamental Research Grant Scheme (FRGS) vot. No. R.J130000.7828.4F721

\section{References}

1. K. Ho, S. Newman, Int. J. Mach. Tool. Manu., 43, 1287 (2003)

2. K.H. Ho, S.T. Newman, S. Rahimifard, R.D. Allen, Int. J. Mach. Tool. Manu., 44, 1247 (2004).

3. J.T. Huang, Y.S. Liao, Int. J. Prod. Res., 41, 1707 (2003)

4. R.V. Rao, V. Kalyankar, Int. J. Adv. Manuf. Technol., 73, 1159 (2014)

5. A.M. Deris, A.M. Zain, R. Sallehuddin, Procedia Eng., 24, 308 (2011)

6. M.R.H. Mohd Adnan, A. Sarkheyli, A.M. Zain, H. Haron, Artif. Intell. Rev., 43, 345, (2013)

7. S. Padhee, N. Nayak, S.K. Panda, P.R. Dhal, S.S. Mahapatra, Sadhana-Acad. P. Eng. S., 37, 223 (2012) 
8. A.M. Zain, H. Haron, S.N. Qasem, S. Sharif, Appl. Math. Model., 36, 1477 (2012)

9. S.N. Joshi, S.S. Pande, Appl. Soft. Comput., 11, 2743 (2011)

10. K.M. Tsai, P.J. Wang, J. Mater. Process. Tech., 117, 111 (2001)

11. S. Assarzadeh, M. Ghoreishi, Int. J. Adv. Manuf. Tech., 39, 488 (2008)

12. G. Krishna Mohana Rao, G. Rangajanardhaa, D. Hanumantha Rao, M. Sreenivasa Rao, J. Mater. Process. Tech., 209, 1512 (2009)

13. A. Mohamad, A.M. Zain, N.E.N. Bazin, A. Udin, J. Intell. Manuf., 26, 1247 (2013)

14. A.F. Kamaruzaman, A.M. Zain, S.M. Yusuf, A. Udin, Appl. Mech. Mater., 421, 496 (2013)

15. N. Zainal, A.M. Zain, N.H.M. Radzi, M.R. Othman, J. Intell. Manuf., 27, 797 (2016)

16. N.F. Johari, A.M. Zain, N.H. Mustaffa, A. Udin, Appl. Mech. Mater., 815, 268 (2015)

17. N. Yusup, A.M. Zain, S.Z.M Hashim, Expert. Syst. Appl., 39, 9909 (2012)

18. D. Kanagarajan, R. Karthikeyan, K. Palanikumar, J.P. Davim, Int. J. Adv. Manuf. Technol., 36, 1124 (2008)

19. K. Deb, A. Pratap, S. Agarwal, T. Meyarivan, IEEE Trans. Evol. Comput., 6, 182 (2002) 